\title{
EVALUASI TINGKAT KETIDAKTEPATAN PEMBERIAN KODE DIAGNOSIS DAN FAKTOR PENYEBAB DI RUMAH SAKIT X JAWA TIMUR
}

\author{
Nurmalinda Puspitasari*, Diah Retno Kusumawati* \\ *STIKES Yayasan Rumah Sakit Dr. Soetomo \\ Email: Nurmalindaps@gmail.com
}

\begin{abstract}
ABSTRAK
Ketepatan kode diagnosa dapat berpengaruh terhadap analisis pembiayaan pelayanan kesehatan khusus dalam kelancaran proses pengklaiman, pelaporan nasional morbiditas dan mortalitas, tabulasi data pelayanan kesehatan bagi proses evaluasi perencanaan pelayanan medis, menentukan bentuk pelayanan yang harus direncanakan dan dikembangkan sesuai kebutuhan zaman dan untuk penelitian epidemiologi dan klinis.. Tujuan penelitian ini adalah mengevaluasi tingkat ketidaktepatan dan faktor-faktor penyebab ketidaktepatan pemberian kode diagnosis di Rumah Sakit X jawa Timur. Jenis penelitian adalah penelitian deskriptif dengan studi retrospektif. Populasi adalah seluruh BRM bulan Januari-Maret 2017 dan sampel yang diambil sebanyak 634 BRM rawat jalan dan rawat inap. Analisis data secara deskriptif. Hasil penelitian menunjukkanterdapat 504 kode diagnosis terkode pada BRM dan 130 tidak terkode pada BRM. Tingkat ketidaktepatan kode diagnosis didapat sebanyak 305 BRM (61\%) yang tepat, 31 BRM (6\%) yang tepat sebagian, dan 168 BRM (33\%) yang tidak tepat. Faktor-faktor penyebab meliputi pengetahuancoder, ketidaklengkapan informasi penunjang medis, ketidaksesuain penggunaan singkatan dengan daftar singkatan Rumah Sakit, dan keterbacaan diagnosis.
\end{abstract}

Kata Kunci : Pengodean, Kode, Diagnosis, Rawat Inap, Rawat Jalan

\begin{abstract}
The accuracy od code diagnosis can affect the of health care financing specifically analysis in the smooth process of claiming, national repot morbidity and mortality, healthcare data tabulation servces for the evaluation prosess of planning medical process of planning medical servicel for the evaluation process of planning medical services, to determine the type of services that must be planned and developed according to the needs of the time and for epidemiological and clinical studies. The purpose of this study to evaluation the accuracy diagnostic code and factors that effect in $X$ Hospital East Java. This research used descriptive with retrospective study. The population was all of medical records in JanuaryMarch 2017 and taken samples of 634 inpatient and outpatientmedical records. Date anlisys by desciptive analisy. The results of the research shows 504 diagnostic code encoded and 130 diagnostic code not encoded in medical records. The accuracy of the diagnosis code, obtained 305 medical records (61\%) accutare, 31 medical records (6\%) partially acurrate and 168 medical records (33\%) inaccurate. Factors that affecting inaccuracies code diagnosis were knowledge of coder, incompleted of medical information, incompatibility of medical records abbreviations with hospital abbreviations, and diagnostic readability.
\end{abstract}

Keywords : Coding, Code, Diagnostic, Inpatient, Outpatient 
PENDAHULUAN

Kodefikasi diagnosa (coding) merupakan kegiatan mengubah diagnosis penyakit menjadi kode yang terdiri dari huruf dan angka. Kegiatan yang dilakukan dalam coding salah satu diantaranya yaitu kegiatan pengodean diagnosis penyakit dan pengodean tindakan medis.

Berdasarkan SK Menteri Kesehatan Nomor 377/Menkes/SK/III/2007 tentang Standar Profesi Perekam Medis dan Informasi Kesehatan dijelaskan bahwa salah satu kompetensi perekam medis adalah klasifikasi dan kodefikasi penyakit, masalah-masalah yang berkaitan dengan kesehatan dan tindakan medis.

Penentuan kode diagnosis yang tepat juga dipengaruhi olehtenaga medis dalam menetapkan kode, tenaga rekam medis sebagai pemberi kode, dan tenaga kesehatan lainnya. Kualitas data terkode merupakan hal penting bagi kalangan tenaga personil manajemen informasi kesehatan, fasilitas asuhan kesehatan, dan para profesional manajemen informasi kesehatan. Ketepatan data diagnosis sangat penting dibidang manajemen data klinis, penagihan kembali biaya, beserta hal-hal lain yang berkaitan dengan asuhan dan pelayanan kesehatan. Ketepatan pemberian kode diagnosis berpengaruh terhadap statistik morbiditas, masalah tentang epidemiologi dan pengambilan keputusan.
Hasil survei pendahuluan yang dilakukan terhadap 20 BRM rawat inap di Rumah Sakit X Jawa Timur menunjukkan bahwa tingkat ketepatan pemberian kode diagnosis sebanyak 7 BRM dengan persentase 35\% dan tingkat ketidaktepatan pemberian kode diagnosis sebanyak 13 BRM dengan persentase 65\%. Ketidaktepatan pemberian kode diagnosis dikarenakan penentuan digit ke-4 yang salah dan diagnosis yang tidak dikode secara lengkap.

Dari hasil observasi awal tersebut sehingga melatar belakangi penulis ingin malakukan penelitian mengenai Evaluasi Tingkat Ketidaktepatan Pemberian Kode Diagnosis dan Faktor Penyebab di Rumah Sakit X Jawa Timur.

\section{METODE}

Jenis penelitian yang digunakan adalah peneltian deskriptif. Penelitian deskriptif yaitu penelitian yang menggambarkan tingkat ketidaktepatan pemberian kode diagnosis kemudian mencari faktor-faktor penyebabnya dengan pengumpulan data melalui studi retrospektif. Studi retrospektif artinya pengumpulan data dimulai dari efek atau akibat yang telah terjadi.Rancangan penelitian yang digunakan adalah penelitian evaluasi untuk menilai suatu pelaksanaan kegiatan yang sedang dilakukan dalam rangka mencari umpan 
balik yang akan dijadikan dasar untuk memperbaiki suatu program atau sistem (Notoatmodjo, 2005)

Rancangan Penelitian termasuk rancangan penelitian evaluasi, yaitu untuk menilai suatu pelaksanaan kegiatan ketidaktepatan pemberian kode diagnosis dan faktor-faktor penyebab di Rumah Sakit X Jawa Timur.

Populasi dalam penelitian ini adalah seluruh BRM rawat jalan dan rawat inap di Rumah Sakit X Jawa Timur bulan Januari-Maret 2017 dengan jumlah 4280 BRM rawat jalan dan rawat inap. Teknik pengambilan sampel menggunakan Simple Random Sampling. Jumlah sampel yang diambil 634 BRM yang terdiri dari 358 BRM rawat jalan dan 276 BRM rawat inap. Pengumpulan data dengan observasi pada BRM dengan menggunakan lembar checklist dan pemberian kuesioner, kemudian data dianalisis menggunakan analisis deskritif untuk mengidentifikasi dan mengevaluasi tingkat ketidaktepatan kode diagnosis dan faktor penyebabnya.

\section{HASIL}

1. Tingkat KetidaktepatanPemberian Kode Diagnosis

Tabel 1 Ketidakterisian Kode Diagnosis Pada BRM

\begin{tabular}{cccc}
\hline No & Kunjungan & Terisi & $\begin{array}{c}\text { Tidak } \\
\text { Terisi }\end{array}$ \\
\hline 1 & Rawat Jalan & 271 & 87 \\
\hline 2 & Rawat Inap & 233 & 43 \\
\hline & Total & 504 & 130 \\
\hline
\end{tabular}

Berdasarkan Tabel 1 dapat diketahui 504 BRM kode diagnosis tidak terisi pada BRM dan 130 BRM kode diagnosis yang terisi pada BRM.

Dari 504 BRM yang kode diagnosisnya terisi dapat diidentifikasi ketidaktepatan pemberian kode diagnosis sebagai berikut:

Tabel 2 Tingkat Ketidaktepatan Pemberian Kode Diagnosis

\begin{tabular}{|c|c|c|c|c|c|c|c|}
\hline \multirow{2}{*}{ No } & \multirow[t]{2}{*}{ Unit } & \multicolumn{2}{|c|}{ Tepat } & \multicolumn{2}{|c|}{$\begin{array}{c}\text { Tepat } \\
\text { Sebagian }\end{array}$} & \multicolumn{2}{|c|}{$\begin{array}{l}\text { Tidak } \\
\text { Tepat }\end{array}$} \\
\hline & & & $\%$ & $\mathrm{n}$ & $\%$ & $\mathrm{n}$ & $\%$ \\
\hline 1 & $\begin{array}{l}\text { Rawat } \\
\text { Jalan }\end{array}$ & 174 & 64 & 8 & 3 & 89 & 33 \\
\hline 2 & $\begin{array}{l}\text { Rawat } \\
\text { Inap }\end{array}$ & 131 & 56 & 23 & 10 & 79 & 34 \\
\hline & Total & 305 & 61 & 31 & 6 & 168 & 33 \\
\hline
\end{tabular}

Berdasarkan Tabel 2 dapat dilihat Tingkat ketidaktepatan pemberian kode diagnosis di Rumah Sakit X Jawa Timur Bulan Januari s/d Maret 2017 dengan jumlah 504 BRM yang terisi diagnosisnya diperoleh hasil pemberian kode diagnosis yang tepat sebanyak 305 BRM (61\%) rawat jalan dan rawat inap, tepat sebagian sebanyak 31 BRM (6\%) rawat jalan dan rawat inap, sedangkan tidak tepat sebanyak 168 BRM (33\%) rawat jalan dan rawat inap.

Berdasarkan hasil tersebut maka tingkat ketidaktepatan kode diagnosis di Rumah Sakit X Jawa Timurdengan total sebesar 168 BRM rawat jalan dan BRM rawat inap dengan persentase 33\% masuk dalam katagori kurang. 
Tingkat ketidaktepatan pemberian kode diagnosis masing-masing unit pelayanan pada bulan Januari s/d Maret 2017 dapat dilihat dalam bentuk grafik pada gambar 1 dan gambar 2 berikut

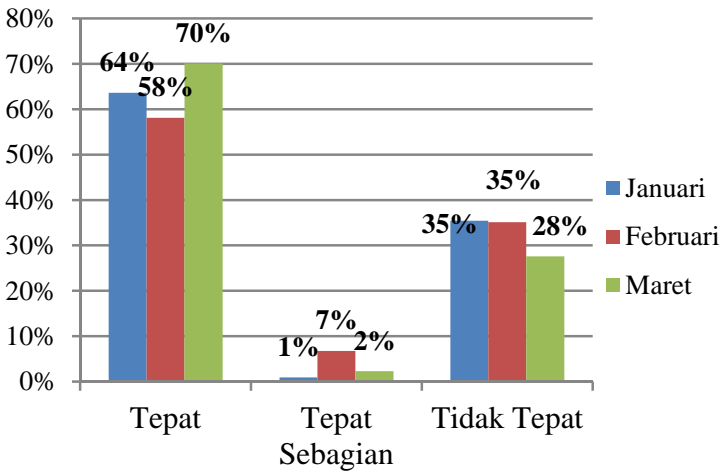

\section{Gambar 1. Tingkat Ketidaktepatan Pemberian Kode Diagnosis Rawat Jalan}

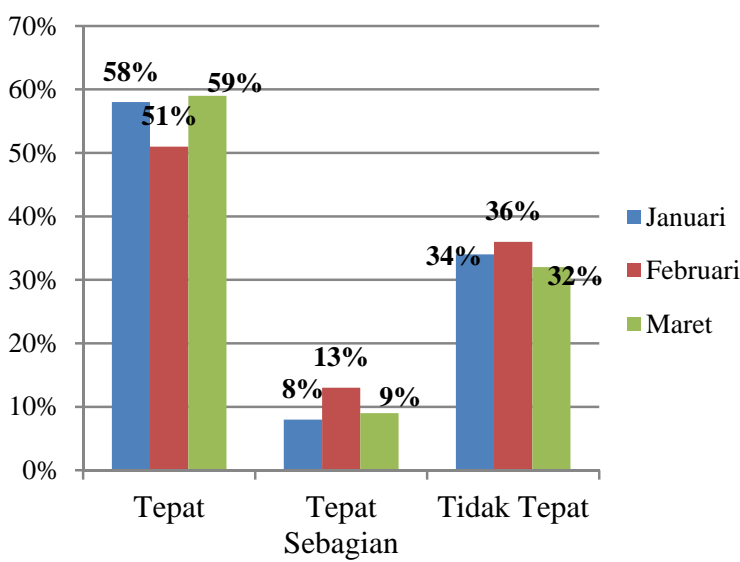

Gambar 2. Tingkat Ketidaktepatan Pemberian Kode Diagnosis Rawat Inap

2. Faktor-Fator Penyebab Tingkat Ketidaktepatan Pemberian Kode Diagnosis

a. Tingkat Pengetahuan Coder

Tabel 3 Karakteristik PendidikanCoder

\begin{tabular}{|c|c|c|c|}
\hline No & Pendidikan & $\begin{array}{c}\text { Jumlah } \\
\text { Responden }\end{array}$ & $\%$ \\
\hline 1 & SMA & 10 & 83 \\
\hline 2 & $\begin{array}{ll}\text { D3 } & \text { Rekam } \\
\text { Medis } & \end{array}$ & 2 & 17 \\
\hline & Jumlah & 12 & 100 \\
\hline
\end{tabular}

Berdasarkan Tabel 3 diketahui 2 codermemilikilatar belakang pendidikan D3 Rekam Medis, dimana 2 coder tersebut melakukan pengodean diagnosis BRM rawat jalan dan rawat inap, sedangkan 10 coderyang memilikilatar belakang pendidikan SMA hanya melakukan pengodean pada lembar SEP dibagian pendaftaran.

Tabel 4 Tingkat Pengetahuan Coder

\begin{tabular}{clcc}
\hline No & Kriteria & $\begin{array}{c}\text { Jumlah } \\
\text { Responden }\end{array}$ & \% \\
\hline 1 & Baik & 2 & 17 \\
\hline 2 & $\begin{array}{l}\text { Cukup } \\
\text { Baik }\end{array}$ & 3 & 25 \\
\hline 3 & $\begin{array}{l}\text { Kurang } \\
\text { Baik }\end{array}$ & 7 & 58 \\
\hline & Jumlah & 12 & $100 \%$ \\
\hline & Berdasarkan & Tabel 4 & diketahui
\end{tabular}
sebanyak 2 coder atau $17 \%$ memiliki tingkat pengetahuan yang baik, 3 coder atau 25\% memiliki tingkat pengetahuan cukup baik dan sebanyak 7 coderatau 58\% memiliki tingkat pengetahuan kurang baik dalam memahami mengenai terminologi medis, pengodean, tata cara coding dan ketentuan dalam ICD-10

b. Kelengkapan Informasi Penunjang Medis

Tabel 5 Kelengkapan Informasi Penunjang Medis

\begin{tabular}{cccccccc}
\hline No & Unit & \multicolumn{2}{c}{ Lengkap } & \multicolumn{2}{c}{ Tidak } & \multicolumn{2}{c}{ Tidak } \\
& & lengkap & \multicolumn{2}{c}{ dibutuhkan } \\
\cline { 3 - 7 } & $\mathrm{n}$ & $\%$ & $\mathrm{n}$ & $\%$ & $\mathrm{n}$ & $\%$ \\
\hline 1 & $\begin{array}{c}\text { Rawat } \\
\text { Jalan }\end{array}$ & 0 & 0 & 7 & 2 & 351 & 98 \\
\hline 2 & $\begin{array}{c}\text { Rawat } \\
\text { Inap }\end{array}$ & 226 & 82 & 25 & 9 & 25 & 9 \\
\hline Total & 226 & 36 & 32 & 5 & 376 & 59 \\
\hline
\end{tabular}


Berdasarkan Tabel 5 diketahui bahwa 226 BRM yang lengkap pemeriksaan penunjangnya keseluruhan dari BRM rawat inap. Sedangkan 32 BRM (5\%) infomasi pemeriksaan penunjang medis yang tidak lengkap hanya 7 BRM (2\%) rawat jalan dan 25 BRM (9\%) rawat inap. Selain itu terdapat 376 BRM (59\%) rawat jalan dan rawat inap yang terdiri dari 351 BRM (98\%) rawat jalan dan 25 BRM (9\%) rawat inap tidak membutuhkan pemeriksaan penunjang dalam menegakkan diagnosis medis.

c. Pengunaan Singkatan

Tabel 6 Kesesuain Penggunaan Singkatan

\begin{tabular}{|c|c|c|c|c|c|c|c|}
\hline \multirow[t]{2}{*}{ No } & \multirow[t]{2}{*}{ Unit } & \multicolumn{2}{|c|}{ Lengkap } & \multicolumn{2}{|c|}{$\begin{array}{c}\text { Tidak } \\
\text { lengkap }\end{array}$} & \multicolumn{2}{|c|}{$\begin{array}{c}\text { Tidak } \\
\text { dibutuhkan }\end{array}$} \\
\hline & & $\mathrm{n}$ & $\%$ & $\mathrm{n}$ & $\%$ & $\mathrm{n}$ & $\%$ \\
\hline 1 & $\begin{array}{l}\text { Rawat } \\
\text { Jalan }\end{array}$ & 0 & 0 & 7 & 2 & 351 & 98 \\
\hline 2 & $\begin{array}{c}\text { Rawat } \\
\text { Inap }\end{array}$ & 226 & 82 & 25 & 9 & 25 & 9 \\
\hline & Total & 226 & 36 & 32 & 5 & 376 & 59 \\
\hline
\end{tabular}

Berdasarkan Tabel 6diketahui 144 BRM (23\%) sesuai dengan daftar singkatan yang telah dibakukan oleh rumah sakit, dengan rincian 85 BRM (24\%) rawat jalan dan 59 BRM (21\%) rawat inap. Sedangkan yang tidak sesuai dengan daftar singkatan hanya sejumlah 174 BRM (27\%) dengan 11 BRM (3\%) rawat jalan dan 163 BRM (59\%) rawat inap. Pada pelaksaaannya juga ditemukan BRM yang tidak menggunakan singkatan sejumlah 316 BRM (50\%) rawat jalan dan rawat inap

d. Keterbacaan Diagnosis

Tabel 7 Keterbacaan Diagnosis

\begin{tabular}{cccccc}
\hline No & Unit & \multicolumn{2}{c}{ Terbaca } & \multicolumn{2}{c}{$\begin{array}{c}\text { Tidak } \\
\text { Terbaca }\end{array}$} \\
\cline { 3 - 6 } & & $\mathrm{n}$ & $\%$ & $\mathrm{n}$ & $\%$ \\
\hline $\mathbf{1}$ & $\begin{array}{c}\text { Rawat } \\
\text { Jalan }\end{array}$ & 262 & 73 & 96 & 27 \\
\hline $\mathbf{2}$ & $\begin{array}{c}\text { Rawat } \\
\text { Inap }\end{array}$ & 158 & 57 & 118 & 43 \\
& Total & 420 & 66 & 214 & 34 \\
\hline
\end{tabular}

Berdasarkan Tabel 7 diketahui diagnosis yang terbaca dengan baik sebanyak 420 BRM (66\%) yang terdiri dari 262 BRM (73\%) rawat jalan dan 158 BRM (57\%) rawat inap. Sedangkan diagnosis BRM yang tidak dapat terbaca berkurang jumlahnya yaitu 214 BRM (34\%) yang teridiri dari 96 BRM (27\%) rawat jalan dan 118 BRM (43\%) rawat inap.

Apabila diagnosis pada BRM tidak dapat terbaca, maka peneliti mengidentifikasi diagnosis lain pada lembar catatan pasien terintegrasi dan lembar rekam medis lain dan atau menanyakan pada petugas rekam medis ruangan selaku coder.

3. Evaluasi Tingkat Ketidak tepatan Pemberian Kode Diagnosis dan FaktorFaktor Penyebab

a. Terdapat beberapa kode diagnosis yang tidak terisi atau tidak tertulis pada BRM 
b. Terdapat beberapa BRM yang memiliki diagnosis rangkap tidak dikode dengan lengkap

c. Terdapat beberapa pemberian kode diagnosis tidak menyertakan digit ke 4, padahal diagnosis tersebut harus dilengkapi digit ke 4 nya sesuai buku ICD 10 volume 1.

d. Petugas rekam medis kurang teliti dalam membaca keterangan diagnosis sehingga ditemukan beberapa kode diagnosis kurang spesifik yaitu menggunakan digit ke 4 dengan .9.

\section{PEMBAHASAN}

1. Tingkat KetidaktepatanPemberian Kode Diagnosis

Tata cara pemberian kode diagnosis di Rumah Sakit X Jawa Timur sudah dibakukan berdasarkan No.Dokumen $\quad$ SPO/179/07/II/2016 tentang SPO Pengkodean Diagnosa Penyakit.

Pemberian Kode Diagnosis di Rumah Sakit X Jawa TimurBulan Januari-Maret 2017 sejumlah 168 BRM rawat jalan dan rawat inap. Dari hasil tersebut dapat diketahui tingkat ketidaktepatan pemberian kode diagnosis di Rumah Sakit X Jawa Timur masuk dalam katagori kurang.

Semakin tinggi tingkat ketidaktepatan pemberian kode diagnosis maka semakin tidak baik kualitas kode diagnosis yang dituliskan pada BRM, sebaliknya semakin rendah tingkat ketidaktepatan pemberian kode diagnosis maka semakin baik kualitas kode yang dituliskan pada BRM.

Beberapa ketidaktepatan pemberian kode diagnosis dikarenakan penentuan digit ke 4 yang tidak tepat pada kode diagnosis rawat jalan dan tidak disertakannya digit ke 4 pada kode diagnosis rawat inap.

Dalam buku ICD volume 2 mengenai petunjuk penggunaan ICD 10, subkatagori karakter ke 4 digunakan untuk identifikasi, misalnya variasi tempat yang berbeda pada katagori 3 karakter untuk penyakit tunggal, atau penyakit yang berdiri sendiri pada katagori 3 karakter untuk group kondisi. Karakter ke 4 seperti $\quad .8$ biasanya digunakan untuk kondisi "Others” pada katagori 3 karakter dan .9 digunakan untuk menyampaikan kondisi yang sama artinya dengan judul katagori ke 3 tanpa informasi tambahan. Jika terjadi ketidakakuratan pengodean, maka akan mempengaruhi indeks pencatatan penyakit, pelaporan morbiditas dan mortalitas, pembiayaan klinis.

\section{Faktor-Faktor Penyebab. Pengetahuan Coder}

Berdasarkan hasil kriteria penilain tingkat pengetahuan, diketahui 2 coder 
masuk dalam katagori baik yaitu dengan latar belakang pendidikan D3 Rekam Medis, dan 10 codermemiliki tingkat pengetahuan cukup baik dan kurang baik yaitu dengan latar belakang pendidikan SMA.

Oleh karenanya perlu ditingkatkan pengetahuan dan pemahaman coder khususnya mengenai fungsi tanda baca pada ICD-10 velume 1, pemahaman tentang terminologi medis dan penentuan digit ke 5, terutama bagi petugas coder dengan latar belakang pendidikan SMA. Perlu pula dilakukan penambahan petugas rekam medis lulusan D3 Rekam Medis, dimana kompetensi dalam melakukan kodefikasi penyakit hanya dimiliki oleh Profesi Perekam Medis dan Informasi Kesehatan.

Sesuai Surat Keputusan Menteri Kesehatan RI Nomor Nomor 377/Menkes/SK/III/2007, salah satu 7Kompetensi perekam medis yang berkaitandengan penelitian ini dan harus dikuasai adalah Klasifikasi dan Kodefikasi Penyakit, Masalah-Masalah yang Berkaitan dengan Kesehatan dan Tindakan Medis, yang menunjukkan pentingnya kemampuan ini bagi seorang ahli madya perekam medis

Pemahaman mengenai terminologi medis, pengodean, tata cara coding dan ketentuan dalam ICD-10 menjadi sangat penting karena dapat menunjang kualitas pengodean. Sebagai perekam medis yang mempunyai kompetensi, coder harus memiliki pengetahuan tentang penggunaan ICD-10 dan cara menentukan kode yang benar.

\section{Kelengkapan Info. Penunjang Medis}

Informasi Penunjang Medis Rumah Sakit X Jawa TimurBulan JanuariMaret 2017 yang tidak lengkap hanya sejumlah 32 BRM (5\%).

Berdasarkan hasil observasi pada BRM, pemeriksaan penunjang yang tidak lengkap diantaranya hasil pemeriksaan USG atau hasil pemeriksaan laboratorium tidak tertempel.

Dalam melakukan observasi pada BRM, informasi pemeriksaan penunjang dikatakan tidak lengkap apabila hasil pemeriksaan penunjang yang tertempel pada lembar penempelan hasil pemeriksaan penunjang dengan pemeriksaan penunjang yang diperintahkan dokter pada lembar catatan perkembangan pasien terintegrasi (RM.RI 09) atau lembar catatan medis awal rawat inap (RM.RI.05) dan lembar asesmen awal medis kebidanan instalasi rawat jalan (RMK 28d) sesuai.

Misalnya, pada BRM rawat inap dengan diagnosis plasenta previa totalis, namun tidak terlampir pemeriksaan penunanjang untuk USG. Setelah 
melakukan review, ditemukan pada lembar catatan medis awal rawat inap tertulis hasil USG menunjukkan PPT (Plasenta Previa Totalis). Selain itu plasenta previa hampir selalu dapat didiagnosis dengan menggunakan ultrasonografi (USG) abdomen, yang 95\% dapat dilakukan setiap saat

Kelengkapan hasil pemeriksaan penunjang medis mempengaruhi ketepatan pemberian kode diagnosis karena dapat dijadikan sebagai informasi pendukung apabila diagnosis yang ditetapkan oleh tenaga medis kurang jelas atau tidak lengkap. Menurut Abdelhak (2001), pengkodeanharus dilaksanakan secara berurutan agar tidakterjadi kesalahan dalam melakukannya. Sebelum melakukan proses pengkodean, petugas rekammedis harus memeriksa kelengkapan lembarrekam medis dan kelengkapan catatan dokter,terutama catatan tentang diagnosis yang tertulispada lembar ringkasan masuk dan keluar dansudah terdapat tanda tangan dokter.

\section{Penggunaan Singkatan}

Berdasarkan Instrumen Akreditasi Rumah Sakit Standar Akreditasi Versi 2012 Bab 6 Manajemen Komunikasi dan Informasi (MKI), dijelaskan pada Standar MKI.13 bahwa rumah sakit menggunakan standar kode diagnosis, kode prosedur/tindakan, simbol, singkatan dan definisi, termasuk singkatan diagnosis dan daftar "yang tidak boleh digunakan” juga distandarisasi.

Rumah sakit X Jawa Timur telah memiliki daftar simbol dan singkatan yang dibakukan, namun terdapat 174 BRM (27\%) tidak sesuai dengan daftar singkatan yang dibakukan rumah sakit. Dari hasil observasi rekam medis ditemukan beberapa singkatan diagnosis yang sering digunakan oleh dokter namun tidak terdapat pada daftar singkatan, sehingga perlu dilakukan penambahan singkatan. Misalnya beberapa singkatan yang sering digunakan oleh dokter namun tidak terdapat pada daftar singkatan rumah sakit yaitu: AUB, KEK, PN, PP, NA, SMK, BSC, KPP, TEV, TTN, KMK, APB, dan PD. Hal ini bertujuan untuk menyeragamkan pemahaman terutama dalam melakukan pengkodean sehingga tidak akan menyulitkan petugas coding dalam melakukan pengkodean penyakit.

\section{Keterbacaan Diagnosis}

Menurut Keputusan Menteri Kesehatan Republik Indonesia Nomor 129/MENKES/SK/II/2008 pasal 2 ayat (1) rekam medis harus dibuat secara tertulis, lengkap dan jelas atau secara elektronik. Pasal 3 menyebutkan salah satu isi rekam medis adalah diagnosis. 
Dokter sebagai pembuat rekam medis harus menetapkan diagnosis secara jelas. Namun di Rumah Sakit X Jawa Timurmasih ditemukan 214 BRM rawat jalan dan rawat inap yang tidak dapat terbaca.

Untukmengurangi ketidaktepatan pemberian kode diagnosis dikarenakan diagnosis yang tidak terbaca, maka sesuai Savitri Citra Budi (2011), penetapan diagnosis pasien merupakan hak, kewajiban, dan tanggung jawab tenaga medis yang memberikan perawatan pada pasien. Apabila ada hal yang kurang jelas, tenaga rekam medis mempunyai hak dan kewajiban menanyakan atau berkomunikasi dengan tenaga medis yang bersangkutan.

3. Evaluasi Tingkat Ketidak tepatan Pemberian Kode Diagnosis dan FaktorFaktor Penyebab Kode Diagnosis Tidak Terisi pada BRM

Ditemukan 130 BRM rawat jalan dan rawat inap tidak terisi kode diagnosisnya. Menurut pemaparan petugas coder, kode diagnosis yang tidak tertulis pada BRM tetap terkode pada billing system rumah sakit namun terdapat beberapa yang tidak dituliskan pada BRM. Dijelaskam dalam SPO Pengodean Diagnosis Penyakit Rumah Sakit X Jawa Timurbahwa tata cara pengodean juga dilakukan dengan input data BRM pada komputer koding.

Sesuai dengan Keputusan Menteri Republik Indonesia Nomor 1333/MENKES/XII/1999 tentang Standar Pelayanan Rumah Sakit, Standar Pelayanan Rekam Medis dan Manajemen Informasi Kesehatan ditetapkan bahwadokter, perawat dan tenaga kesehatan lainnya bertanggung jawab akan kebenaran dan ketepatan pengisian rekam medis yang diatur dalam anggaran dasar peraturan dan panduan kerja rumah sakit bahwa semua rekam medis diberi kode dan di indeks dalam waktu 14 hari setelah pasien pulang.

Pelaksanaan pengodean di Rumah Sakit X Jawa Timur sebaiknya juga melengkapi kode diagnosis pada BRM, karena pada dasarnya reakm medis dikatakan bermutu apabila akurat, lengkap, dapat dipercaya, valid dan tepat waktu (Abdelhak, 2001). Salah satu bentuk pengelolaan dalam rekam medis adalah pendokumentasian serta pengkodean (coding) diagnosis. Pelaksanaan pengkodean dilakukan oleh tenaga perekam medis dengan menggunakan standar klasifikasi internasional. 
Diagnosis pada BRM tidak dikode dengan lengkap

Misalnya pada BRM rawat jalan poli kandungan dengan diagnosis kontrol post SC, petugas rekam medis hanya memberikan kode Z48.8 (Other specified surgical follow-up care). Ditemukan 68 diagnosis kontrol post SC yang tidak menyertakan kode SC. Seharusnya diagnosis tersebut diberi kode tambahan SC O82.0 (Delivery by elective caesarean section) jika dilakukan SC yang telah direncakan sebelumnya. Penambahan kode SC dimaksudkan untuk memperjelas asuhan bedah apa yang diberikan pada pasien.

Dari 183 BRM ditemukan 172 BRM rawat jalan dan rawat inap memiliki diagnosis rangkap, namun beberapa diagnosis rangkap tidak dikode lengkap. Menurut Gemala R. Hatta (2008), untuk pelaporan secara kelompok bagi analisis penyebab tunggal morbiditas yang diambil adalah kode kondisi utama, sedangkan untuk pengindekan kode semua kondisi ini harus dicatat, dikode untuk kemudian disimpan agar dapat memenuhi kebutuhan setempat yang lebih luas.

\section{Tidak disertakannya digit ke 4}

Salah satunya pada diagnosis BBLR (Berat Badan bayi Lahir Rendah), pada lembar resume medis rawat inap diberi kode P07 (Disorders related to short gestation and low birth weight, not elsewhere classified). Kode P07 terbagi menjadi 4 subkatagori 4 karakter, yaitu P07.0 (Extremely low birth weight) untuk berat lahir bayi 999 gram atau kurang, P07.1 (Other low birth weight) untuk berat lahir bayi antara 1000-2499 gram, P07.2 (Extreme immaturity) untuk kehamilan kurang dari 28 minggu lengkap, dan P07.3 (Other preterm infants) untuk kehamilan 28 minggu sampai kurang dari 37 minggu lengkap.

Seharusnya petugas rekam medis dalam memberikan kode diagnosis BBLR dengan menyertakan karakter atau digit ke 4 sesuai dengan ICD 10 volume 1. Pemberian kode diagnosis BBLR untuk karakter ke 4 disesuaikan dengan keterangan berat lahir bayi yang dituliskan pada BRM.

Pada dasarnya ICD adalah suatu daftar kode tunggal katagori 3 karakter, dimana 3 karakter dapat dibagi dalam karakter yang ke 4 setelah titik desimal hingga 10 subkatagori. Bila katagori 3 karakter tidak dibagi maka dianjurkan untuk menambah huruf " $X$ " pada posisi ke 4. Subkatagori 4 karakter digunakan paling tepat untuk identifikasi karena menunjukkan kode yang lebih spesifik. 
Petugas Rekam Medis Kurang Teliti Dalam Melakukan Review BRM

Misalnya pemberian kode diagnosis rawat jalan poli kandungan untuk kontrol hamil lanjutan resiko tinggi yaitu Z35.9. Kode kontrol hamil lanjutan resiko tinggi terbagi menjadi 10 subkatagori 4 karakter. Berdasarkan hasil review, semua diagnosis kode kontrol hamil lanjutan resiko tinggi terkode Z35.9. Seharusnya beberapa kode diagnosis kontrol hamil lanjutan resiko tinggi tidak dikode dengan Z35.9 karena terdapat riwayat kesahatan dan riwayat persalinan pasien yang dijelaskan pada lembar assesment keperawatan instalasi rawat jalan dan lembar assesmant awal medis kebidanan instalasi rawat jalan. Misalnya kontrol hamil lanjutan resiko tinggi dengan riwayat persalinan melahirkan bayi 6 kali atau lebih, maka diagnosis seharusnya dikode Z35.4 (Supervision of pregnancy with grand multiparity).

Sebaiknya penggunaan subkatagori karakter ke 4 yaitu untuk .9 digunakan apabila pada BRM tidak dituliskan keadaan yang lebih spesifik, tetapi apabila ditemukan diagnosis dengan keterangan lebih spesifik sebaiknya menggunakan karakter ke 4 yang sesuai dengan keadaan tersebut.
Penting bagi petugas rekam medis selaku coder memperoleh gambaran yang jelas secara menyeluruh dari dokumentasi rekam medis tentang masalah dan asuhan yang diterima pasien. Karena keakuratan kode diagnosis yang dituliskan pada BRM merupakantanggung jawab petugas rekam medis.

\section{SIMPULAN}

Tingkat ketidaktepatan pemberian kode diagnosis di Rumah Sakit X Jawa Timur bulan Januari-Maret 2017 sejumlah 168 BRM (33\%) rawat jalan dan rawat inap. Masuk dalam katagori kurang.

Faktor-faktor yang mempengaruhi tingkat ketidaktepatan pemberian kode diagnosis di Rumah Sakit X Jawa Timur, yaitu:

Pengetahuan Coder

Kelengkapan informasi penunjang medis

\section{Penggunaan singkatan \\ Keterbacaan diagnosis}

Hasil evaluasi tingkat ketidaktepatan pemberian kode diagnosis dan faktor penyebab:

Beberapa kode diagnosis tidak tertulis pada BRM

Beberapa diagnosis tidak dikode dengan lengkap

Tidak disertakannya digit ke 4 
Petugas RM kurang teliti dalam melakukan review BRM

\section{DAFTAR PUSTAKA}

Abdelhak, M. 2001. Health Information Management of Strategic Resource. Sydney: W.B Saunders Company.

Budi, Savitri Citra. (2011). Manajemen Unit Kerja Rekam Medis. Yogyakarta : Quantum Sinergis Media

Hatta, Gemala R. 2008. Pedoman Manajemen Informasi Kesehatan di Sarana Pelayanan Kesehatan. Jakarta : Universitas Indonesia.

Keputusan Menteri Kesehatan Republik Indonesia Nomor 129/Menkes/SK/II/2008 tentang
Standar Pelayanan Mininal di Rumah Sakit.

Keputusan Menteri Kesehatan Republik Indonesia Nomor 377/Menkes/SK/III/2017 tentang Standar Profesi Perekam Medis.

Keputusan Menteri Republik Indonesia Nomor 1333/MENKES/XII/1999 tentang Standar Pelayanan Rumah Sakit.

Kemenkes RI. 2012. Standar Akreditasi Rumah Sakit. Kerjasama Direktorat Jenderal Bina Upaya Kesehatan Kementerian Kesehatan Republik Indonesia dengan Komisi Akreditasi Rumah Sakit (KARS).Jakarta

Notoatmodjo, Soekidjo. 2005. Metodologi Penelitian Kesehatan Edisi Revisi. Jakarta : Dirjen Yanmed. 